\title{
Manufactures Animal Prescription Drugs
}

National Cancer Institute

\section{Source}

National Cancer Institute. Manufactures Animal Prescription Drugs. NCI Thesaurus. Code C114889.

A business that makes prescription veterinary products. 